\title{
PECULIARITIES OF EDUCATIONAL ORIENTATION OF TEENAGERS WITH DIFFERENT TYPES OF INTERPERSONAL PERCEPTION OF THE GROUP
}

\author{
MSc Zholudeva Miroslava Valerievna, Southern Federal University, Rostov-on-Don, Russia \\ E-mail: miroslazz@yandex.ru
}

Dr. Zholudeva SvetlanaVasilievna, Department of Organizational and Developmental Psychology, Academy of Psychology and Pedagogy, Southern Federal University, Rostov-on-Don, Russia

E-mail: ZholudevaSV@yandex.ru

ARTICLE INFO

Original Article

Received: August, 22.2016.

Revised: October, 29.2016.

Accepted: November, 07.2016. doi:10.5937/IJCRSEE1602041V

UDK

159.953.5.072-053.6(470)"2016"

37.064 .3

\section{Keywords:}

group,

interpersonal perception, educational

orientation,

orientation on a grade,

orientation on assessment,

a teenager.
A B S T R A C T

In this research the peculiarities of educational orientation in the course of learning at the selection of 86 teenagers depending on perception of the educational group by them have been studied. Reliability of the research has been provided with the use of the relevant techniques: "Interpersonal perception in the group" (Ilyin E. P., 2002) "Orientation on knowledge acquisition" and "Orientation on a grade" (Ilyin E. P., 2002). It has been specified that the teenagers with individualistic, collectivistic and pragmatical types of interpersonal perception of the group are oriented to different extents on a grade and knowledge in the course of learning. The provided data can be used by school psychologists, counseling psychologists, in aid of teachers and parents.

(c) 2016 IJCRSEE. All rights reserved.

\section{INTRODUCTION}

The knowledge of a person by a person is one of the topical issues of social psychology. In the theoretical terms its development is closely connected with the problems of communication, activities, personality, consciousness, self-consciousness, etc. Interpersonal knowledge serves as the necessary attribute of labor and educational activity, in fact, how people reflect and interpret character and behavior, as well as estimate the personality of each other, the type of their interaction and the results of their joint activities depend in many respects (Slinkova V. E., 2007).

\section{Corresponding Author}

Dr. Zholudeva SvetlanaVasilievna, Department of Organizational and Developmental Psychology, Academy of Psychology and Pedagogy, Southern Federal University, Rostov-on-Don, Russia

E-mail: ZholudevaSV@yandex.ru

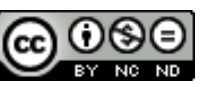

This work is licensed under a Creative Commons Attribution - NonCommercial - NoDerivs 4.0. The article is published with Open Access at www.ijcrsee.com
In general three directions of researches are distinguished in the area of perception depending on what is the object of perception (other person, group, wider social community). "Social self-perception", the process and the result of the reflexive part of interpersonal interaction also belong to the same range of problems. The structure of interpersonal perception is described as three-component. It includes the object, the subject and the process itself which should be considered in the context of the specific situation. According to the special researches upon studying of the situation of interpersonal perception the most important factor is joint activity, especially goals, subject-matter and forms of organization of this activity (Pavlova T., 2014). In the scientific literature it is underlined again and again that there are peculiarities of perception and understanding of other people and themselves by teenagers with different level of interpersonal relations (Balavadze T. Sh., 2009), regularities of determination of the processes of interpersonal perception taking into account the real group dynamics in the conditions of isolation (Vinokhodova A. G., 1997), interrelation of professional tendencies 
and professional interests with the type of the group perception of teenagers (Zholudeva M. V., Zholudeva S. V., 2016), age dynamics of precision and adequacy of interpersonal perception (Samekin A. S., 2011), peculiarities of formation of interpersonal perception as condition of teenagers' communication improvement (Berezina A. V., 2003), etc.

The main new feature appearing in a teenager's psychology in comparison with a child of the primary school age is higher level of self-consciousness. Along with it there is well-defined demand to evaluate correctly and use the available opportunities, form and develop abilities, bringing them to the level where they are in adults. At this age teenagers become more sensitive to the opinion of the people of their age and adults. It is supposed that the person knows himself through communication with other people therefore development of interpersonal perception is important not only in itself, but also it is necessary for formation of self-consciousness and development of reasonable self-esteem.

Communication with the people of the same age becomes the leading activity of teenage years. Just at the beginning of teenage years communication activities, conscious testing with own relations with other people (search of friends, getting into an argument, conflicts and reconciliations, change of groups of friends) are allocated into a rather independent area of life. The main requirement of the period - to find your own place in the society, to be "significant" - are realized in the community of the people of the same age. At the same time a teenager continues to remain a pupil; educational activities keep the relevance. Therefore the research dedicated to the peculiarities of educational orientation of teenagers with different types of interpersonal perception of the group is especially urgent.

\section{MATERIALS AND METHODS}

Founding on theoretical underpinning of the set up problem, we have studied the peculiarities of educational orientation of teenagers with different types of interpersonal perception of the group. The hypothesis of the research has acted as presumption that there are peculiarities of educational orientation of teenagers with different types of interpersonal perception of the group.

As empirical tasks, we have put forward the following:

1. To define the type of interpersonal perception of the group of teenagers;

2. To describe the peculiarities of orientation on a grade of teenagers with different types of interpersonal perception of the group;

3 . To describe the peculiarities of orientation on knowledge of teenagers with different types of interpersonal perception of the group.

The pupils-teenagers of the 9th form have acted as respondents in the research. In total 86 persons have taken part in the research. The research has been conducted at the Municipal Educational Institution of Secondary Education "School No. 75" of Rostovon-Don.

At the first stage of the diagnostic testing we have used the technique "Interpersonal perception in the group" T. Leary, G. Leforge, R. Sazek (Ilyin E. P., 2011) allowing to reveal three possible "types" of perception by the individual of the group. Upon that the role of the group in the individual activity of the percipient acts as an indicator of the perception type.

At the second stage of the diagnostic testing we have used 2 techniques: "Orientation on knowledge acquisition" and "Orientation on a grade" put forward by E. P. Ilyin and N. A. Kurdyukova (Ilyin E. P., 2002). In the course of the technique realization "Orientation on knowledge acquisition" the degree of demand manifestation on knowledge acquisition has been revealed. The technique results "Orientation on a grade" have allowed revealing the degree of demand manifestation of teenagers for getting a grade.

At the third stage of the empirical research, the results received by us, have undergone the quantitative processing and the qualitative analysis according to the following scheme:

1. According to the technique "Interpersonal perception in the group" T. Leary, G. Leforge, R. Sazek, the dominating type of interpersonal perception of teenagers who have taken part in the research (collectivistic, pragmatical, individualistic) has been defined (Ilyin E. P., 2011). For proving of the put forward hypothesis and convenience of description of the obtained data according to the results of the technique the teenagers have been conditionally divided into three groups (according to the type of perception by the individual of the group): Group 1, Group 2 and Group 3:

Group 1 - the teenagers with individualistic type of perception;

Group 2 - the teenagers with pragmatical type of perception;

Group 3 - the teenagers with collectiv- 
istic type of perception.

Processing, analysis and interpretation of the obtained empirical data have been carried out according to the distinguished groups.

2. According to the techniques of E. P. Ilyin and N. A. Kurdyukova "Orientation on knowledge acquisition" and "Orientation on a grade" the expressiveness degree of motivation on knowledge and a grade have been determined (Ilyin E. P., 2002).

At the fourth stage of our research for statistical check of the put forward hypothesis Mann-Whitney U-Test and Kruskal-Wallis Test have been used, by means of which the distinctions in orientation on knowledge or a grade of teenagers with different types of perception of the group have been specified.

Also Spearmen's rank-order correlation has been used by means of which the significant correlation pleiades between the data of the techniques "Interpersonal perception in the group" (Ilyin E. P., 2011) and the techniques of E. P. Ilyin and N. A. Kurdyukova "Orientation on knowledge acquisition" and "Orientation on a grade" (Ilyin E. P., 2002) in Groups 1, 2, 3 have been revealed.

\section{RESULTS}

Studying of perception by the teenagers of the group has shown that most of the teenage respondents $(40.7 \%)$ are with individualistic type of perception of the group. Such teenagers perceive the group as hindrance of their activities or treat it neutrally. The group has not been represented as independent value for them. It is revealed in evading from joint forms of activities, in preference of individual work, in restriction of contacts.

Thirty-six percent of teenagers are with collectivistic type of perception of the group. They perceive the group as independent value. The problems of the group and its separate members come to the foreground for them, interest in both success of each member of the group, and the group in general, aspirations to make your own contribution to the group activities is observed. The need for collective forms of work is developed.

The smallest number of teenagers is with pragmatical type of perception of the group $(23.3 \%)$. Such teenagers perceive the group as the means promoting achievement of these or those individual goals. Under that the group is perceived and estimated from the point of view of its "usefulness" for the individual. The preference is given to more com- petent members of the group capable to render assistance, to undertake the solution of a complex problem or to be a source of the necessary information.

Further according to the put forward objectives we have divided all teenagers into the previously described groups, depending on the type of perception of the group.

For checking of justice and correctness of separation of the teenagers into the groups we have carried out the statistical analysis by means of nonparametric Kruskal-Wallis $\mathrm{H}$-Test. The obtained results are provided in Table 1. So, significant distinctions have been revealed in all scales that testifies about rightfulness of separation of the teenagers into the groups.

Table 1. Test Statistics (a, b) Types of perception of the group

\begin{tabular}{lccc}
\hline & Individualistic & Collectivistic & Pragmatical \\
\hline Chi-Square & 51.947 & 56.068 & 46.259 \\
\hline df & 2 & 2 & 2 \\
\hline Asymp. Sig. & 0.000 & 0.000 & 0.000 \\
\hline & & \\
a Kruskal Wallis Test \\
b Grouping Variable: Group
\end{tabular}

Thus, the analysis of interpersonal perception by teenagers of the group has shown that for the teenagers who have taken part in the research to perceive the group as the means promoting achievement of these or those individual goals is peculiar in a lesser extent. They are more aimed at individual work, and joint activities and the group in general are not perceived as value for them. And most often, on the contrary, it is perceived as hindrance of own activities.

For research of educational orientation we have carried out the analysis of the data on orientation on a grade and orientation on knowledge. Description and analysis are presented according to the previously distinguished groups meeting the goals and the objectives of our research.

In Figure 1 the results of motivation of teenagers on knowledge acquisition are provided. So, in most of teenagers of all groups $(65.5 \%, 68 \%$ and $75 \%)$ the average level of motivation on knowledge acquisition has been revealed. They feel mental and physical involvement in educational activities, in what is currently doing. They have partial concentration of attention, thoughts and feelings in practice. They do not always know precisely what to do at this or that moment of work, do not always clearly realize its goals and objectives, they are characterized by partial subordination to the requirements going from the 
activities themselves; they partially realize the fact, how well, how successfully they do their work, they do not always give a clear and specific feedback on the activities.

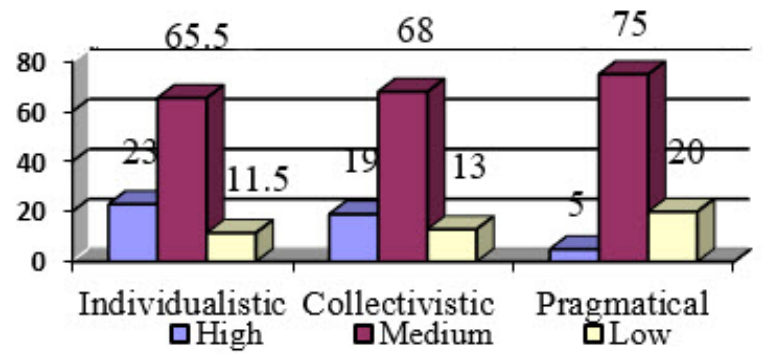

Figure 1. Level of orientation of teenagers on knowledge acquisition (in \%)

Twenty-three percent of teenagers with individualistic type, $19 \%$ with collectivistic type and $5 \%$ with pragmatical type of the group perception have high level of motivation on knowledge acquisition. Such teenagers look for change of impressions, new information, feel need for the process of knowledge, goal-oriented activity. If such teenagers aspire to special area of knowledge, then on this basis their interests and addictions arise, develop, and become stronger. Irrespective of the problems of adaptation to a definite situation their informative requirement is oriented, first of all, to the process of cognition. "Unselfishness" of the informative requirement, its orientation mainly to the process, but not to the result - the most important characteristic of teenagers with high level of orientation on knowledge acquisition.

Eleven and a half percent of teenagers with individualistic type, $13 \%$ with collectivistic type and $20 \%$ with pragmatical type of the group perception have been revealed with low level of orientation on knowledge acquisition. Such teenagers are characterized by unstable informative requirement, their interests often change. They do not use the efforts for solution of the stated goal and objectives, adapt to a situation more. They are not inclined to analyze the failure reasons in their activities.

Thus, the average level of orientation on knowledge acquisition has been revealed approximately in an equal number of teenagers of all groups. High level has been detected in the majority of teenagers of individualistic type of the group perception, and low level in teenagers of pragmatical type.

Further for detection of significant distinctions in orientation on knowledge acquisition we have applied non-parametric Mann-Whitney U-Test. We have analyzed the distinctions in pairs in the groups of teenagers with different types of the group perception. So, significant distinctions of orientation on knowledge acquisition have been revealed in teenagers of individualistic and pragmatical types of the group perception where $U=167.000$, at $r=0.006$. The average rank in the group of teenagers of individualistic type is equal to 30.40 and teenagers of pragmatical type -21.80 . These distinctions indicate that the teenagers with individualistic perception of the group the orientation on knowledge acquisition is higher.

In Figure 2 the results of orientation on a grade of teenagers are presented. So, least of teenagers have been revealed with high level of orientation on a grade in all groups. In the group with individualistic perception $-8.5 \%$, with collectivistic perception -6.55 , and in the group with pragmatical perception teenagers with high level have not been revealed. It shows that these teenagers are focused to compare the grades with the grades of their schoolmates, they remember when they get the poor grades, worry about the results of the forthcoming tests very much, and their mood often depends on the progress at school.

The average level of orientation on a grade has been revealed in most of teenagers of all groups. So, $93.5 \%$ of teenagers with collectivistic, $65.5 \%$ with individualistic, and $45 \%$ with pragmatical group perception follow how often they are called to the blackboard by the teacher, do their best to prepare for the next lessons even if they were asked at the previous lesson and experience some anxiety in anticipation of the testing.

Most of teenagers with low level of orientation on a grade have been revealed in the group with pragmatical perception $-55 \%$. In the group with individualistic perception -26 $\%$, and in the group with collectivistic perception the teenagers with low level of motivation on a grade have not been revealed. These teenagers do not worry about academic progress at all; they aren't upset when receiving bad grades, their mood doesn't depend on their learning.

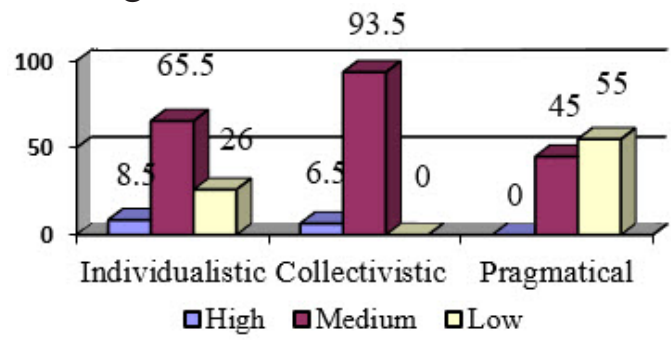

Figure 2. Level of orientation of teenagers on a grade (in \%) 
Thus, the average level of orientation on a grade has been revealed in most of teenagers with collectivistic and individualistic types of the group perception. High level of orientation on a grade has been revealed in most of teenagers of individualistic type, and low - in teenagers of pragmatical type.

Further we have applied the nonparametric Kruskal-Wallis H-Test for detection of significant distinctions in orientation on a grade. We have analyzed distinctions at the same time in all groups of teenagers with different types of the group perception. So, significant distinctions of orientation on a grade have been revealed in teenagers of all types of the group perception where $\mathrm{N}=6.730$, at $\mathrm{r}=0.025$. The average rank in the group of teenagers of individualistic type is equal to 43.44 , collectivistic type -46.68 , and pragmatical type - 29.17. These distinctions indicate that teenagers of collectivistic type of the group perception are guided by grades most of all, and teenagers of pragmatical type - to a lesser extent.

We have carried out the correlation analysis for specification of the peculiarities of educational orientation in teenagers with different types of the group perception. Significant correlation relationships between orientation on knowledge acquisition, orientation on a grade and types of the group perception revealed by means of Spearmen's rank-order correlation are reflected in Table 2.

Table 2. Nonparametric Correlations of orientation on a grade and orientation on knowledge with type of the group perception in teenagers

\begin{tabular}{|c|c|c|c|}
\hline & & Individualistic & Pragmatical \\
\hline \multirow{3}{*}{$\begin{array}{l}\text { Orientation } \\
\text { on } \\
\text { knowledge } \\
\text { acquisition }\end{array}$} & $\begin{array}{l}\text { Correlation } \\
\text { Coefficient }\end{array}$ & $508(* *)$ & $-.596(* *)$ \\
\hline & Sig. (2-tailed) & 0,000 & 0.000 \\
\hline & $\mathrm{N}$ & 86 & 86 \\
\hline \multirow[t]{3}{*}{$\begin{array}{l}\text { Orientation } \\
\text { on a grade }\end{array}$} & $\begin{array}{l}\text { Correlation } \\
\text { Coefficient }\end{array}$ & & $.355(* *)$ \\
\hline & Sig. (2-tailed) & & .001 \\
\hline & $\mathrm{N}$ & & 86 \\
\hline
\end{tabular}

It has been discovered that teenagers with individualistic type of the group perception are aimed at knowledge acquisition where $r=508$, at $p=0.000$. So, the teenagers who perceive the group as hindrance of their activities, and the group has not been represented as independent value for them, are oriented to knowledge acquisition to a large extent, they have an expressed "unselfish" informative requirement, and they are aimed at the process of knowledge to a large extent.

The teenagers of pragmatical type who perceive the group as the means promoting achievement of these or those individual goals and estimate it from the point of view of "usefulness" for them and it is a source for the necessary information, they aren't aimed at knowledge acquisition where $\mathrm{r}=-596$, at $\mathrm{p}=0.000$, and are focused on a grade where $\mathrm{r}=355$, at $\mathrm{p}=0.001$.

\section{DISCUSSION}

The comparative analysis of orientation on knowledge acquisition in teenagers with different types of the group perception has shown that

- in teenagers with individualistic type of the group perception orientation on knowledge acquisition is higher than in teenagers of other groups. They are characterized by "unselfish" informative requirement which is mainly focused on the process, but not on the result. They look for the change of impressions, new information, feel need for the process of knowledge and goal-oriented activity;

- in teenagers with pragmatical perception of the group orientation on knowledge acquisition is expressed least of all. They aren't interested in new educational knowledge, they don't analyze failures in educational activity, and their interests are inconsistent and unstable;

- in teenagers with collectivistic perception of the group the level of orientation on knowledge acquisition is medium. They do not always know precisely what to do at this or that moment of work, do not always clearly realize its goals and objectives, they are characterized by partial subordination to the requirements going from the activities themselves; they partially realize the fact, how well, how successfully they do their work, they do not always give a clear and specific feedback on the activities.

The comparative analysis of orientation on a grade in teenagers with different types of the group perception has shown that

- in teenagers with collectivistic type of the group perception orientation is higher at level, in comparison with other groups of teenagers. These teenagers are more oriented on assessment of their progress. They compare their educational progress with the progress of their schoolmates, worry about the obtained 
bad grades, after getting of a bad grade their working capacity also decreases and in case of complete confidence that they will not be asked, they can come with unprepared material;

- in teenagers with pragmatical type of the group perception orientation on a grade is expressed least of all. These teenagers do not worry about academic progress at all, they aren't focused on reaction of the schoolmates concerning the progress, in most cases they don't worry concerning the forthcoming test and the teacher's interviewing;

- in teenagers with individualistic type of the group perception orientation on a grade is expressed at the medium level. These teenagers are oriented on a grade only in certain cases when the grade can be a condition for obtaining of some benefit.

\section{CONCLUSIONS}

Thus, the analysis of educational orientation in teenagers with different types the group perception has shown that orientation on the group, its values (collectivistic type) promotes the selective orientation on knowledge, and on a grade and depends on the values and the regulations of the group itself. The contrast between yourself and the group, orientation on individual types of activity (individualistic type) promotes the orientation on knowledge. And the use of the group in your own purposes (pragmatical type) develops the orientation on a grade and vice versa reduces the orientation on knowledge.

\section{ACKNOWLEDGMENT}

The authors would like to thank to Doctor of Psychology, Professor of Southern Federal University in Rostov-on-Don, Belousova Alla Konstantinovna, for her positive feedback and comments, which led to a significant improvement in the work.

\section{Conflict of interests}

The authors declare no conflict of interest.

\section{REFERENCES}

Balavadse T. Sh. (2009). Perception and understanding of other people and yourself by teenagers with different levels of interpersonal relations. Doctoral thesis in Psychology. Lomonosov Moscow State University (MSU). Moscow. Retrieved from http://elibrary.ru/item.asp?id=15951837

Berezina A. V. (2003). Peculiarities of formation of interpersonal perception as condition of improvement of communication of teenagers. Doctoral thesis in Psychology. Moscow. Retrieved from http://elibrary.ru/item.asp?id=16002682

Ilyin E.P. (2002). Motivation and motives. PETER, 431-432. Saint-Petersburg.

Ilyin E.P. (2011). Psychology of communication and interpersonal relations. PETER, 507-510. SaintPetersburg.

Kolomenskaya O.Ya (1993). Influence of peculiarities of interpersonal perception on position of the personality in the group. Author's Doctoral thesis in Psychology. St. Petersburg. Retrieved from http://elibrary.ru/item.asp?id=15730159

Pavlova, T. (2014). The relationship between the intensity and the effectiveness of the preschool children in joint mental activity. International Journal Of Cognitive Research In Science, Engineering And Education (IJCRSEE), 2(2), 17-20. Retrieved from http://www.ijcrsee.com/index. php/ijcrsee/article/view/108/262

Samekin A. S. (2011). Age dynamics of accuracy and adequacy of interpersonal perception. Doctoral thesis in Psychology. Lomonosov Moscow State University (MSU). Moscow. Retrieved from http://elibrary.ru/item.asp?id=19264949

Slinkova V. E. (2007). Interpersonal perception and relationship of partners in communication. In the collection: Humanitarian knowledge Collection of scientifc articles. Series «Scientifc horizons» under the general edition of V. G. Egorkin. St. Petersburg http://elibrary.ru/item. asp? $\mathrm{id}=24204996$

Vinokhodova A. G. (1997). Interpersonal perception in the isolated small group. Doctoral thesis in Psychology. Moscow.

Zholudeva M. V., Zholudeva S. V. (2016). Peculiarities of interrelation of professional tendencies and professional interests with type of the group perception of teenagers. Professional presentation 1(8), 50-56. Southern Federal University. Rostov-on-Don. Retrieved from http://elibrary. $\mathrm{ru} /$ item.asp? $\mathrm{id}=26606754$ 